\title{
Impact of environmental
} moisture on $\mathrm{C}_{3} \mathrm{~A}$ polymorphs in the absence and presence

\section{of $\mathrm{CaSO}_{4}$ : 0.5 $\mathrm{H}_{2} \mathrm{O}$}

Elina Dubina

PhD student, Technische Universität München, Lehrstuhl für Bauchemie, Munich, Germany

\section{Johann Plank}

Professor and Chair for Construction Chemistry, Technische Universität München, Lehrstuhl für Bauchemie, Munich, Germany
Leon Black

Senior Lecturer in Civil Engineering Materials, Institute for Resilient Infrastructure, School of Civil Engineering, University of Leeds, Leeds, UK Lars Wadsö

Professor, Department of Building Materials, University of Lund, Lund, Sweden

The phenomenon of water vapour sorption by anhydrous $C_{3} A$ polymorphs both in the absence and in the presence of $\mathrm{CaSO}_{4} \cdot \mathbf{0 . 5} \mathrm{H}_{2} \mathrm{O}$ was studied utilising dynamic and static sorption methods. It was found that orthorhombic $\mathrm{C}_{3} \mathrm{~A}$ starts to sorb water at $55 \%$ relative humidity $(\mathrm{RH})$ and cubic $\mathrm{C}_{3} \mathrm{~A}$ at $80 \% \mathrm{RH}$. Also, $\mathrm{C}_{3} \mathrm{~A}_{\mathrm{o}}$ sorbs a higher amount of water which is predominantly physically bound, whereas $C_{3} A_{c}$ preferentially interacts with water by chemical reaction. In the presence of calcium sulfate hemihydrate, ettringite was observed as the predominant pre-hydration product for both $\mathrm{C}_{3} \mathrm{~A}$ modifications: that is, ion transport had occurred between $\mathrm{C}_{3} \mathrm{~A}$ and sulfate. Environmental scanning electron microscopic imaging revealed that in a moist atmosphere, a liquid water film condenses on the surface of the phases as a consequence of capillary condensation between the particles. $C_{3} A$ and sulfate can then dissolve and react with each other. Seemingly, pre-hydration is mainly facilitated through capillary condensation and less through surface interaction with gaseous water molecules.

\section{Notation}

$d_{50} \quad$ calcium aluminate hydrate phases average particle size

$M_{t} \quad$ amount of water sorbed by the sample at time $t$

$p \quad$ water $\left(\mathrm{H}_{2} \mathrm{O}\right)$ under actual test conditions

$p_{0} \quad$ partial water pressure at saturation

$R \quad$ universal gas constant

$r \quad$ radius of the pores or initial spaces

$t$ time

$W_{0} \quad$ weight of the sample at the beginning of the experiment

$W_{t} \quad$ weight of the sample at sorption time $t$

$\sigma \quad$ surface tension of water

$\rho \quad$ density of the sample

\section{Introduction}

Ordinary Portland cement (OPC) is a moisture-sensitive material and may take up water vapour during the manufacturing process or later on by inappropriate conditions occurring during its transport or storage (Hansen and Clausen, 1974; Richartz, 1973; Sprung, 1978). The phenomenon of water vapour sorption by cement powder exposed to humidity is known as pre-hydration of cement (Breval, 1977; Jensen et al., 1999). Pre-hydration of cement may lead to failures that are more prevalent in climates characterised by high temperatures and humidities. In previous works, several consequences of pre-hydration for the chemical and engineering properties of cement have been reported. These include: increased setting time, decreased compressive strength and heat of hydration, altered rheological properties and poor response to superplasticiser addition (Deng et al., 2002; Maltese et al., 2007; Schmidt et al., 2007; Sylla, 1975; Theisen and Johansen, 1975; Whittaker et al., 2013; Winnefeld, 2008).

In order to secure control of cement performance in the field and thus also of concrete performance, it is important to understand the mechanisms behind the interactions of cement with water vapour. Owing to the complex nature of cement, it is challenging to identify the key processes occurring during sorption of water on the surfaces of cement particles. Previous studies have shown that the individual clinker minerals $\mathrm{C}_{3} \mathrm{~S}, \mathrm{C}_{2} \mathrm{~S}, \mathrm{C}_{3} \mathrm{~A}$ and $\mathrm{C}_{4} \mathrm{AF}$ have fundamentally different sensitivities to moisture (Dubina et al., 2010; Jensen, 1995).

The current authors have investigated the physicochemical effects of water sorption on the surfaces of pure individual clinker phases, plus those of different sulfates and free lime (Dubina et al., 2011). The authors determined the relative humidity (RH) thresholds at which early-stage hydration (up to $11 \mathrm{~h}$ ) of these cement constituents in moist atmospheres started to occur, and the amount of water sorbed per unit of surface area. The 
experiments demonstrated that among all cement components, orthorhombic $\mathrm{C}_{3} \mathrm{~A}$ and free lime were the ones which started to sorb water at particular low RH values $(<55 \%)$. Additionally, they sorbed the highest amounts of water. Cubic $\mathrm{C}_{3} \mathrm{~A}$ and $\mathrm{C}_{4} \mathrm{AF}$ followed next, while $\mathrm{C}_{3} \mathrm{~S}$ and $\mathrm{C}_{2} \mathrm{~S}$, the main clinker constituents, were the least reactive phases.

However, the study of pre-hydration of individual cement constituents does not account for interactions between different phases, which can take place during pre-hydration of actual cements. For example, it is well established that at the early stage of its hydration with liquid water, $\mathrm{C}_{3} \mathrm{~A}$ can react with sulfates to form $\mathrm{AF}_{\mathrm{m}}$ or $\mathrm{AF}_{\mathrm{t}}$ phases (Black et al., 2006; Brown et al., 1984; Minard et al., 2007; Pourchet et al., 2009). Thus, formation of those phases may significantly affect further sorption of water vapour by cement. Furthermore, Kirchheim et al. (2009) showed that there are important differences between the hydration of the two $\mathrm{C}_{3} \mathrm{~A}$ polymorphs (cubic and orthorhombic) with gypsum. Therefore, it is of interest to have a better understanding of the interaction of each $\mathrm{C}_{3} \mathrm{~A}$ polymorph with calcium sulfates when exposed to different relative humidities.

In an earlier study it was reported that cubic $\mathrm{C}_{3} \mathrm{~A}$ reacted with gypsum when it was pre-hydrated (Breval, 1979). Yet there are no studies which compare the behaviour of the two $\mathrm{C}_{3} \mathrm{~A}$ polymorphs (cubic and orthorhombic) when exposed to moisture in the presence of calcium sulfate hemihydrate, and the mechanism underlying this pre-hydration reaction. More specifically, it is unknown whether pre-hydration is solely a reaction between $\mathrm{C}_{3} \mathrm{~A}$ with sulfates and gaseous water vapour, or whether it occurs as a consequence of water vapour condensation, which then allows $\mathrm{C}_{3} \mathrm{~A}$ and sulfate to react in solution.

In this study, specific water sorption experiments were performed to gain an understanding of the principal interactions occurring during pre-hydration between the $\mathrm{C}_{3} \mathrm{~A}$ polymorphs in the absence and presence of calcium sulfate hemihydrate (subsequently abbreviated as 'hemihydrate', and chosen for its higher solubility and dissolution rate compared to gypsum or anhydrite). From this, the behaviours of the two $\mathrm{C}_{3} \mathrm{~A}$ polymorphs were compared.

\section{Materials and methods}

\section{Materials}

Pure, undoped cubic $\mathrm{C}_{3} \mathrm{~A}$ and orthorhombic $\mathrm{C}_{3} \mathrm{~A}$ doped with $4 \mathrm{wt} \% \mathrm{Na}_{2} \mathrm{O}$ were synthesised from calcium carbonate and aluminium oxide according to Dubina et al. (2011). In the preparation of $\mathrm{C}_{3} \mathrm{~A}_{\mathrm{o}}$, sodium nitrate was used as a source for $\mathrm{Na}_{2} \mathrm{O}$. The sintered samples were removed from the oven, allowed to cool in air for $3 \mathrm{~min}$ and then immediately placed in the cup of a ball mill (Planetary Mono Mill Pulverisette 6 classic line, Fritsch, Idar-Oberstein, Germany). Grinding was performed for $10 \mathrm{~min}$ at $250 \mathrm{r} / \mathrm{min}$ at a temperature of $21^{\circ} \mathrm{C}$ and a $\mathrm{RH}$ of $20 \%$. No grinding agent was added in the milling process.

Precautions were taken to prevent reaction with atmospheric carbon dioxide and water vapour by storing the freshly ground samples in sealed $20 \mathrm{ml}$ glass bottles placed in a vacuum desiccator containing silica gel as a drying agent.

According to quantitative X-ray diffraction (XRD) analysis using Rietveld refinement, the $\mathrm{C}_{3} \mathrm{~A}$ phases were $99 \pm 0 \cdot 5 \mathrm{wt} \%$ pure. The XRD patterns of the cubic and orthorhombic $\mathrm{C}_{3} \mathrm{~A}$ samples are presented in Figure 1. Their average particle size ( $d_{50}$ value) and specific surface area (Brunauer-Emmett-Teller (BET), $\mathrm{N}_{2}$ ) are given in Table 1 .

The sample of $\beta$-modification of calcium sulfate hemihydrate (purity $97 \mathrm{wt} \%$ ) was obtained from Sigma-Aldrich (Taufkirchen, Germany). The average particle size and specific surface area were $10.4 \mu \mathrm{m}$ and $12000 \mathrm{~cm}^{2} / \mathrm{g}$, respectively (Table 1). Binary mixtures of individual cubic and orthorhombic $\mathrm{C}_{3} \mathrm{~A}$ respectively with hemihydrate were prepared by manually blending the $\mathrm{C}_{3} \mathrm{~A}$ and hemihydrate powders at a molar ratio of $1: 1$.

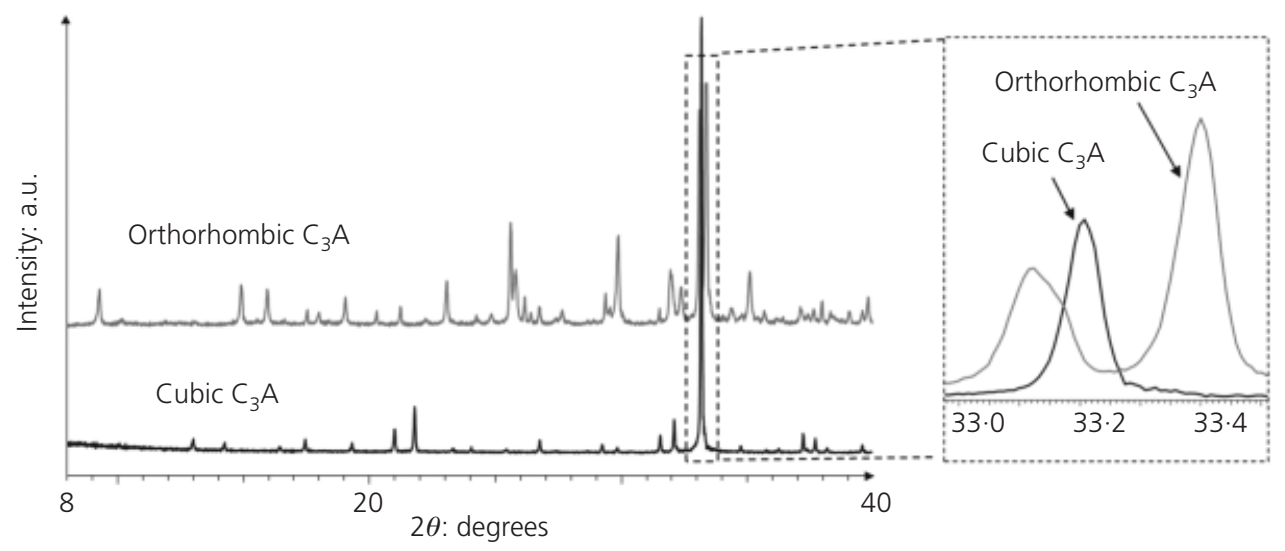

Figure 1. X-ray diffraction patterns of cubic and orthorhombic

$\mathrm{C}_{3} \mathrm{~A}$ phases as prepared, shown in the range of $8-40$ ( $2 \theta$ degrees

scale) 


\begin{tabular}{lcc}
\hline Phase & $\begin{array}{c}\text { Average particle } \\
\text { size }\left(d_{50} \text { value): }\right. \\
\mu m\end{array}$ & $\begin{array}{c}\text { Specific surface } \\
\text { area }(\mathrm{BET}): \\
\mathrm{cm}^{2} / \mathrm{g}\end{array}$ \\
\hline Cubic $\mathrm{C}_{3} \mathrm{~A}$ & $6 \cdot 2$ & 7800 \\
Orthorhombic $_{3} \mathrm{~A}$ & $10 \cdot 0$ & 7000 \\
$\mathrm{CaSO}_{4} \cdot 0.5 \mathrm{H}_{2} \mathrm{O}$ & $10 \cdot 4$ & 12000
\end{tabular}

Table 1. Average particle size ( $d_{50}$ value) and specific surface area (BET) of the cubic and orthorhombic $C_{3} A$ modifications prepared for this study

\section{Methods}

\section{Exposure of samples to water vapour}

For the determination of the water vapour sorption behaviour of the various samples, both dynamic and semi-equilibrium (static) water sorption methods were used. In both experiments, the temperature was held constant at $20^{\circ} \mathrm{C}$.

A sorption balance (DVS Advantage, Surface Measurement Systems Ltd, London, UK) was used to measure the moisture uptake using the dynamic method. Further details on this instrument and the general set-up can be found in Dubina et al. (2011). For analysis, $0 \cdot 015-0 \cdot 05 \mathrm{~g}$ of a binary mixture $\left(\mathrm{C}_{3} \mathrm{~A}+\right.$ hemihydrate) were placed in a sample pan, which was then transferred into a climate chamber where the desired $\mathrm{RH}$ was obtained by mixing a proportional amount of dry and humid nitrogen gas. Two different exposure protocols were used during the dynamic vapour sorption tests, as described below.

In the first regime, $\mathrm{RH}$ was continuously increased from $1 \%$ to $95 \% \mathrm{RH}$ at a constant rate of approximately $0 \cdot 16 \% \mathrm{RH}$ per minute, as described in Dubina et al. (2011). This ramp regime provided a mass change profile and made it possible to assess the threshold value of RH (onset point) at which a sample started to sorb water. In the second regime, $\mathrm{RH}$ was increased from $1 \%$ to $95 \% \mathrm{RH}$ in $10 \% \mathrm{RH}$ steps to the desired $\mathrm{RH}$ and then kept at this level, as shown in Figure 2. The duration of exposure at each RH was set at either $1 \mathrm{~h}$ for short-duration experiments and at $5 \mathrm{~h}$ for

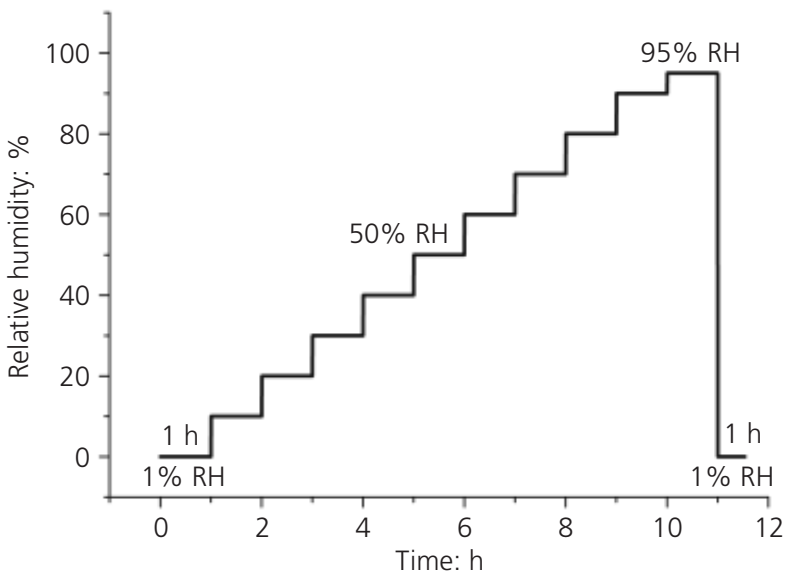

Figure 2. Test protocol for the dynamic water vapour sorption experiment whereby relative humidity is increased in $1 \mathrm{~h}$ steps over time

long-duration experiments. At the beginning and end of each experiment, $\mathrm{RH}$ was set to $1 \% \mathrm{RH}$.

In this study, physically bound water is defined as water which can be removed by drying at $1 \% \mathrm{RH}$ for $1 \mathrm{~h}$ only, while nonremovable water was considered to be bound chemically (irreversibly sorbed).

For the semi-equilibrium (static) regime the relative humidity environment was realised by keeping the samples $(0 \cdot 15-0 \cdot 50 \mathrm{~g})$ in a desiccator above saturated salt solutions. Exposure period was $21 \mathrm{~d}$. The salts used and their relative humidity values are given in Table 2.

For the experiments in the presence of calcium sulfate hemihydrate, the binary mixtures were weighed accurately (this value was designated as $W_{0}$ ), and then stored for $21 \mathrm{~d}$ at a constant temperature of $20^{\circ} \mathrm{C} \pm 1^{\circ} \mathrm{C}$ under different relative humidities. The weight increase of the samples at sorption time $t$ was measured by quickly weighing them on a digital balance. This

\begin{tabular}{lccccccc}
\hline Salt & $\mathrm{K}$-acetate & $\mathrm{MgCl}_{2}$ & $\mathrm{~K}_{2} \mathrm{CO}_{3}$ & $\mathrm{NaBr}$ & $\mathrm{NaCl}$ & $\mathrm{KCl}$ & $\mathrm{KNO}_{3}$ \\
\hline Concentration: $\mathrm{g} / \mathrm{l}^{\mathrm{a}}$ & 2700 & 700 & 1350 & 1200 & 500 & 500 & 500 \\
$\mathrm{RH}: \%$ & 23 & 33 & 43 & 60 & 75 & 85 & 95 \\
$\mathrm{p}\left(\mathrm{H}_{2} \mathrm{O}\right): \mathrm{kPa}$ & 0.54 & 0.77 & 1.01 & 1.40 & 1.76 & 1.99 & 2.22 \\
\hline
\end{tabular}

a With solid salt at the bottom of the salt solution.

Table 2. The saturated salt solutions used in the experiments, the corresponding relative humidity values at $20^{\circ} \mathrm{C}$ obtained from them and the values for partial water pressure calculated from the saturation vapour pressure of water $(2.34 \mathrm{kPa})$ at

$\mathrm{RH}=100 \%$ (Greenspan, 1977) 
value was noted as $W_{t}$. The weight increases were monitored over a period of $21 \mathrm{~d}$. The percentage mass of water sorbed by a binary mixture at time $t$ was calculated as

$$
\text { 1. } M_{t}=\frac{W_{t}-W_{0}}{W_{0}} \times 100 \%
$$

\section{Instrumentation}

Samples were analysed by quantitative XRD using a Bruker D8 Advance X-ray diffractometer (Bruker AXS, Karlsruhe, Germany) with Bragg - Brentano geometry, equipped with a twodimensional detector (Vantec - 1, Bruker AXS, Karlsruhe, Germany) operated at an accelerating voltage of $40 \mathrm{keV}$ on a $\mathrm{CuK}_{\alpha}$ anode, irradiation intensity of $30 \mathrm{~mA}$, and 40 scans in steps of $0.02 \%$. Cement hydrates were identified by comparison with Diffract Plus EVA Application V.8.0 and JCPDS PDF-2 database (JCPDS, 2003).

The average particle size ( $d_{50}$ value) of all phases tested was measured by laser granulometry (Cilas 1064, Cilas, Marcoussis, France) using isopropyl alcohol as a base fluid and ultrasound to disagglomerate the particles before the measurement.

The specific surface area of all samples was determined by nitrogen adsorption (BET method) employing a Nova 4000e surface area analyser from Quantachrome (Odelzhausen, Germany).

Environmental scanning electron microscopic (ESEM) and scanning electron microscopic (SEM) images were obtained on a FEI XL 30 FEG instrument (FEI, Eindhoven, Netherlands) equipped with a Peltier cooling stage and a gaseous secondary electron detector. One set of samples was investigated under low vacuum conditions ( 1 mbar $\mathrm{H}_{2} \mathrm{O}$ pressure, corresponding to $\sim 4 \% \mathrm{RH}$ at room temperature). Samples were not coated and were examined before and after their exposure to $\mathrm{RH}$ in a sorption balance or in a desiccator over various periods of time.

For selected samples, in situ observations of the development of pre-hydration products were performed using the ESEM mode. For this, anhydrous samples were placed on the cooling stage in the microscope chamber whereupon the temperature was lowered to $3^{\circ} \mathrm{C}$ and the water vapour pressure was raised to $\sim 6.3 \mathrm{mbar}$ (corresponding to $85 \% \mathrm{RH}$ ) for $1.5 \mathrm{~h}$. To allow high-resolution imaging, the pressure was lowered to $\sim 1.7$ mbar (corresponding to $\sim 7 \% \mathrm{RH}$ ) during imaging.

\section{Results and discussion}

Water sorption behaviour of individual $C_{3} A$ polymorphs Total water sorption

Applying the ramp regime, cubic and orthorhombic $\mathrm{C}_{3} \mathrm{~A}$ showed significantly different behaviours (Figure 3). Orthorhombic $\mathrm{C}_{3} \mathrm{~A}$

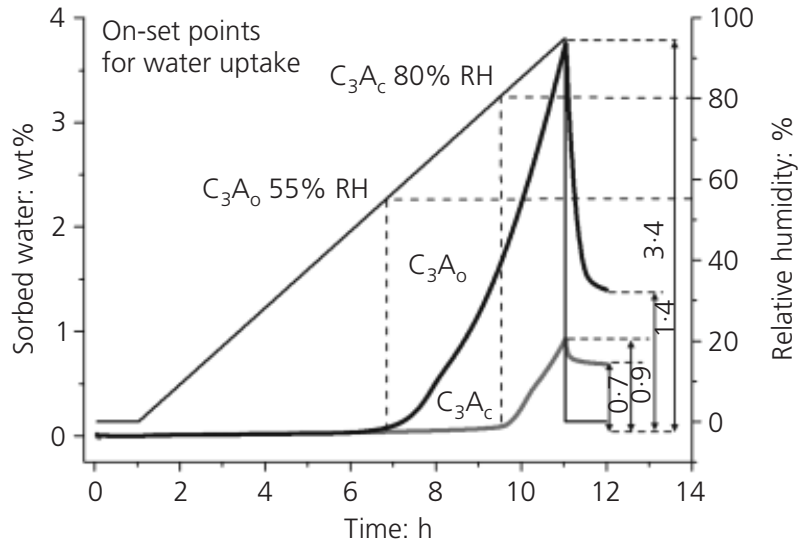

Figure 3. Water vapour sorption isotherms of cubic and orthorhombic $\mathrm{C}_{3} \mathrm{~A}$, determined on a sorption balance at $20^{\circ} \mathrm{C}$ using ramp mode and measured over a period of $11 \mathrm{~h}$

started to sorb water already at $\sim 55 \% \mathrm{RH}$, which is far below the onset point of $80 \% \mathrm{RH}$ observed for cubic $\mathrm{C}_{3} \mathrm{~A}$. This indicates that orthorhombic $\mathrm{C}_{3} \mathrm{~A}$ is more susceptible to moisture than cubic $\mathrm{C}_{3} \mathrm{~A}$.

Under these conditions, when $\mathrm{RH}$ reached $95 \%$, cubic $\mathrm{C}_{3} \mathrm{~A}$ had sorbed $\sim 0.9 \mathrm{wt} \%$ of water, based on its dry mass. Thereafter, when $\mathrm{RH}$ was lowered to $1 \%, 0.7 \mathrm{wt} \%$ could not be removed and thus were considered as bound by chemical reaction. In comparison, orthorhombic $\mathrm{C}_{3} \mathrm{~A}$ had sorbed a total of $\sim 3.4 \mathrm{wt} \%$ of water, with $\sim 1.4 \mathrm{wt} \%$ bound chemically. The water sorption behaviour of the two $\mathrm{C}_{3} \mathrm{~A}$ polymorphs is in line with their relative reactivities in cement hydration. There, it is well established that orthorhombic $\mathrm{C}_{3} \mathrm{~A}$ (which contains a higher amount of $\mathrm{Na}_{2} \mathrm{O}$ dope) is more reactive with sulfate than the cubic $\mathrm{C}_{3} \mathrm{~A}$ polymorph, which is low in $\mathrm{Na}_{2} \mathrm{O}$ content.

Following the water vapour sorption experiment, all samples were analysed by XRD and SEM. XRD revealed no discernible differences between pre-hydrated and fresh samples, with the amount of surface hydrates formed being insignificant compared to the non-reacted bulk material.

However, SEM analysis revealed significant differences in the surface appearance of the two polymorphs (Figure 4). Undoped $\mathrm{C}_{3} \mathrm{~A}_{\mathrm{c}}$ showed considerably fewer pre-hydration products than $\mathrm{C}_{3} \mathrm{~A}_{\mathrm{o}}$. For cubic $\mathrm{C}_{3} \mathrm{~A}$, preferential nucleation of $\mathrm{C}-\mathrm{A}-\mathrm{H}$ phases between grains or on grain edges was observed. For the sodiumdoped $\mathrm{C}_{3} \mathrm{~A}_{\mathrm{o}}$, after water vapour exposure the initially smooth surface was almost completely covered by very fine crystals of $\mathrm{Na}_{2} \mathrm{CO}_{3}$, as indicated by elemental energy-dispersive X-ray (EDX) mapping. Additionally, C-A-H phases were found on the surface.

The presence of alkalis has a major impact on the water vapour sorption behaviour of $\mathrm{C}_{3} \mathrm{~A}$. Orthorhombic $\mathrm{C}_{3} \mathrm{~A}$ shows a tendency 
Advances in Cement Research

Volume 26 Issue 1
Impact of environmental moisture on $\mathrm{C}_{3} \mathrm{~A}$ polymorphs in the absence and presence

of $\mathrm{CaSO}_{4} \cdot 0 \cdot 5 \mathrm{H}_{2} \mathrm{O}$

Dubina, Plank, Black and Wadsö

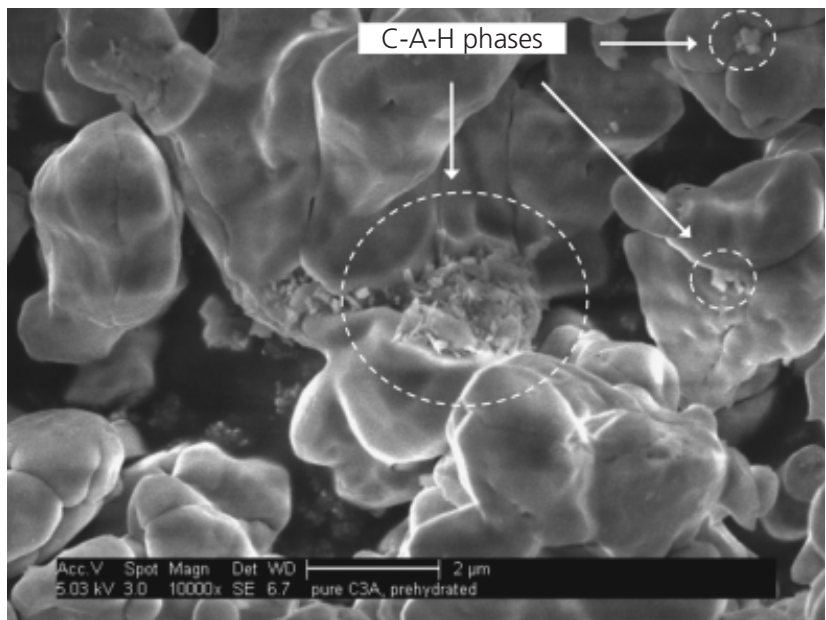

(a)

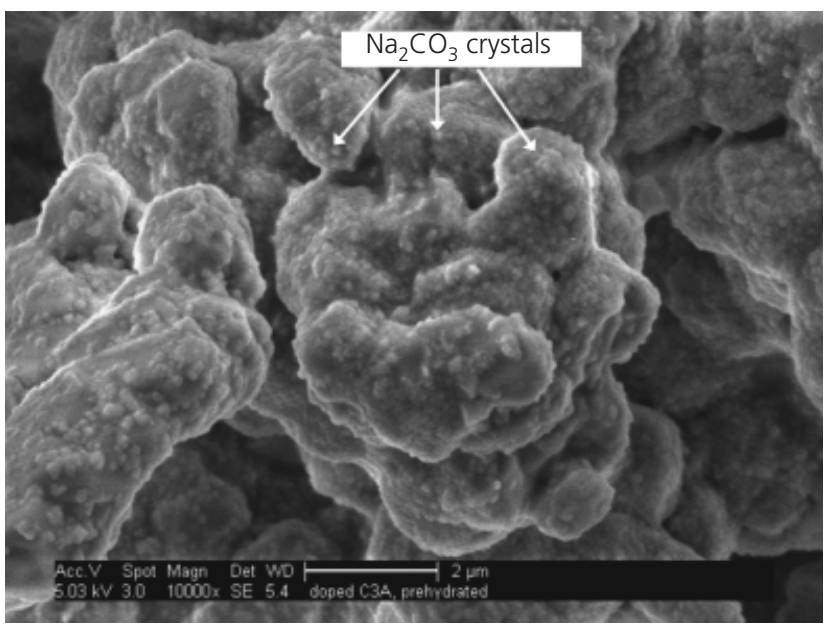

(b)

Figure 4. SEM images of the $\mathrm{C}_{3} \mathrm{~A}$ polymorphs pre-hydrated for $10 \mathrm{~h}$ using ramp regime and subsequent drying at $1 \% \mathrm{RH}$ for $1 \mathrm{hr}$ at $20^{\circ} \mathrm{C}$ : (a) pure, cubic $\mathrm{C}_{3} \mathrm{~A}$; (b) doped, orthorhombic $\mathrm{C}_{3} \mathrm{~A}$

to selectively exclude sodium ions from its crystal structure (Glasser and Marinho, 1984). This process can change both the surface characteristics and also the bulk properties of $\mathrm{C}_{3} \mathrm{~A}$. When orthorhombic $\mathrm{C}_{3} \mathrm{~A}$ comes in contact with water vapour, then it reacts to form $\mathrm{C}-\mathrm{A}-\mathrm{H}$ phases and sodium ions are released as $\mathrm{NaOH}$ which will then quickly undergo carbonation.

Most interesting and important, however, was evidence of condensed water films, occurring mainly in the interstitial spaces and sometimes on the surfaces of the $\mathrm{C}_{3} \mathrm{~A}$ particles exposed to moisture. Figure 5 shows as example an in situ ESEM image of $\mathrm{C}_{3} \mathrm{~A}_{\mathrm{c}}$ exposed for $30 \mathrm{~min}$ to $85 \% \mathrm{RH}$ in the microscope chamber. The micrograph reveals a thin water film which bridged two adjacent $\mathrm{C}_{3} \mathrm{~A}$ particles. Such films were also observed when studying $\mathrm{C}_{3} \mathrm{~A}_{\mathrm{o}}$ samples.

Obviously, interaction of these phases with humidity is not

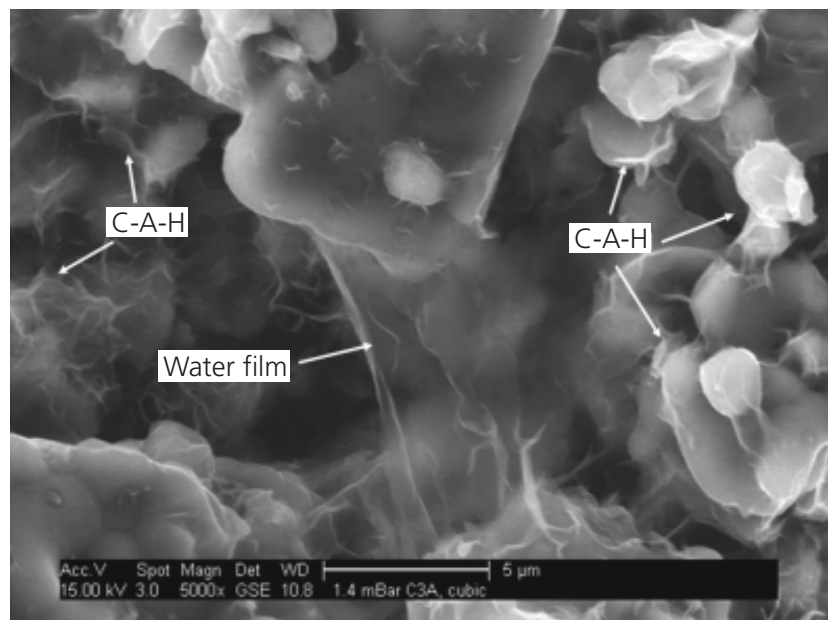

Figure 5. ESEM image of cubic $C_{3} A$, pre-hydrated for 30 min in the ESEM chamber at $4.5^{\circ} \mathrm{C}$ and $85 \% \mathrm{RH}$, exhibiting a film of condensed liquid water between the particles

limited to physicochemical reactions whereby gaseous water molecules first sorb onto the surfaces of the mineral phases and then produce initial hydration products from each individual phase. In the present study, a different mode of interaction was observed involving liquid condensed water, whereby the phases first dissolve, then hydrates resulting even from dissolved ions of two different mineral species are precipitated from an oversaturated solution. This mechanism is based on capillary condensation of water in the interstitial spaces between the clinker particles which can be described by Kelvin's equation

2. $\ln \left(\frac{p}{p_{0}}\right)=-\frac{\sigma}{R T \rho r}$

where $p$ is partial pressure of water under actual test conditions, $p_{0}$ is partial water pressure at saturation, $\sigma$ is surface tension of water, $R$ is a universal gas constant, $\rho$ is density of the sample and $r$ is radius of the pores or initial spaces.

According to Equation 2 it is obvious that the smaller the pore size, the lower the RH at which capillary condensation occurs. In this study, a broad distribution of pore sizes ranging from $50 \mathrm{~nm}$ to $1 \mu \mathrm{m}$ was evident between the $\mathrm{C}_{3} \mathrm{~A}$ particles (Figures 4 and 5). Electron micrographs showed evidence of water films on all samples after only a few minutes of exposure to moist air, and the first hydration products become visible immediately after the films appeared. The amount of hydrates became more abundant with exposure time.

The observation that pre-hydration - at least partially - occurs by way of a liquid film of condensed water is of great significance. It suggests that during the process of pre-hydration, cement constituents can interact with each other in a similar 
manner as during normal hydration after mixing cement with water. This concept was probed further when the binary mixtures of $\mathrm{C}_{3} \mathrm{~A}$ and hemihydrate were tested later. However, it must be considered that the chemical potential of water is decreasing by reducing the water vapour pressure $(\mathrm{RH})$ or by presence of alkali ions (e.g. sodium in orthorhombic $\mathrm{C}_{3} \mathrm{~A}$ ) with high ionic strengths leading to precipitation of hydrates with lower water content than at high water activities, for example during hydration with liquid water (Baquerizo et al., 2012).

\section{Impact of exposure time on water sorption}

The water vapour sorption process is dependent on different factors, such as temperature, exposure time, $\mathrm{RH}$ and specific properties of the material under investigation. As a system may take time to reach equilibrium, the amount of sorbed water may vary with respect to time when the sample is exposed to humidity. To study the impact of storage time on the amounts of chemically and physically bound water, cubic and orthorhombic $\mathrm{C}_{3} \mathrm{~A}$ samples were exposed to humidity using the step mode.

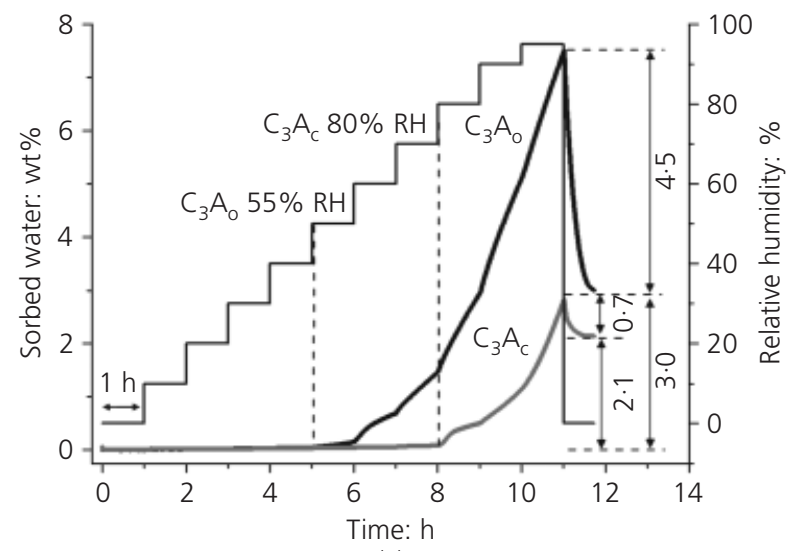

(a)

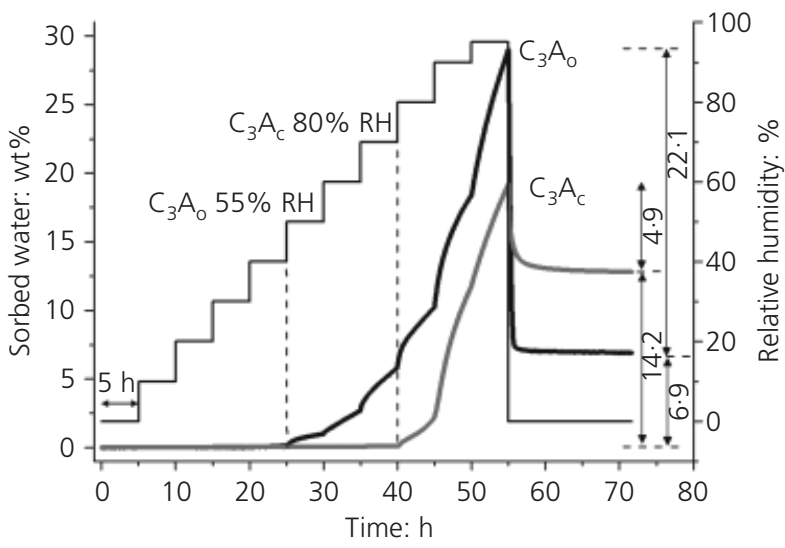

(b)

Figure 6. Water vapour sorption isotherms of cubic and orthorhombic $\mathrm{C}_{3} \mathrm{~A}$, determined on a sorption balance at $20^{\circ} \mathrm{C}$ using the $\mathrm{RH}$ step mode and measured over a total time period of (a) $11 \mathrm{~h}$ and (b) $55 \mathrm{~h}$
Figure 6 shows the time-dependent evolution of mass change for both samples at increased RH. The exposure time for each RH step was increased from $1 \mathrm{~h}$ (short exposure) to $5 \mathrm{~h}$ (long exposure), and the amounts of physically and chemically bound water were calculated based on the initial dried mass of samples.

The extended exposure times had no influence on the thresholds for water uptake. Orthorhombic and cubic $\mathrm{C}_{3} \mathrm{~A}$ samples started to take up noticeable amounts of water vapour at $\mathrm{RH}$ values of $50 \%$ $\mathrm{RH}$ and $80 \% \mathrm{RH}$ respectively (Figure 6). These $\mathrm{RH}$ values are in good agreement with the onset points found before using the ramp regime $\left(55 \% \mathrm{RH}\right.$ for orthorhombic $\mathrm{C}_{3} \mathrm{~A}$ and $80 \% \mathrm{RH}$ for cubic $\mathrm{C}_{3} \mathrm{~A}$; see Figure 3 ). However, the duration of the experiments did affect the total amounts of water sorbed by each sample. When exposed to $5 \mathrm{~h}$ steps, cubic $\mathrm{C}_{3} \mathrm{~A}$ sorbed almost 7 times more water than when exposed to $1 \mathrm{~h}$ steps, whereas orthorhombic $\mathrm{C}_{3} \mathrm{~A}$ sorbed 4 times more water. Despite this, for cubic $\mathrm{C}_{3} \mathrm{~A}$ the ratio between chemically and physically bound water was independent of the duration of the experiment, remaining at $\sim 3$ for both short $(2 \cdot 1 /$ $0.7 \mathrm{wt} \%)$ and long $(14.2 / 4.9 \mathrm{wt} \%)$ exposure. For orthorhombic $\mathrm{C}_{3} \mathrm{~A}$, however, the ratio changed significantly. When humidity was increased in $1 \mathrm{~h}$ steps, the ratio of chemically to physically bound water was 0.7 . It decreased to 0.3 for the experiments applying $5 \mathrm{~h}$ steps. This indicates that under prolonged exposure to humidity, orthorhombic $\mathrm{C}_{3} \mathrm{~A}$ undergoes fewer chemical reactions and preferentially sorbs water physically. Consequently, independent of exposure times, cubic $\mathrm{C}_{3} \mathrm{~A}$ generally predominantly interacts with water vapour through chemical reactions while orthorhombic $\mathrm{C}_{3} \mathrm{~A}$ preferentially sorbs water physically.

Another significant difference was observed in the total amounts of water bound chemically on each sample after drying at $1 \%$ $\mathrm{RH}$. Here, after longer exposure times, cubic $\mathrm{C}_{3} \mathrm{~A}$ bound more water chemically than orthorhombic $\mathrm{C}_{3} \mathrm{~A} \quad(14 \cdot 2 \mathrm{wt} \%$ against $6.9 \mathrm{wt} \%$ ). Characterisation of the samples by XRD after exposure to humidity showed no apparent changes after short exposure (11 h). However, for orthorhombic $\mathrm{C}_{3} \mathrm{~A}$ reflections for katoite $\left(\mathrm{C}_{3} \mathrm{AH}_{6}\right)$ were observed after long exposure (Figure 7). No additional reflections from sodium containing phases (e.g. $\mathrm{Na}_{2} \mathrm{CO}_{3}$ ) were found for the orthorhombic phase.

It should be noted that under real conditions, when a $\mathrm{C}_{3} \mathrm{~A}$ or cement sample is exposed to humid air, no subsequent drying will occur at the end of the exposure period. Thus, the total amount of water sorbed there will also include physically bound water. Additionally, throughout this experiment carbon dioxide was rigorously excluded to minimise the formation of various carbonate species. Such a condition differs significantly from actual storage environments.

\section{Influence of particle size on water sorption}

Another factor which may greatly influence the total amount of water sorbed is the particle size and therefore the specific surface area of a sample and the pore sizes for capillary condensation. To determine the impact of particle size on the water vapour sorption 


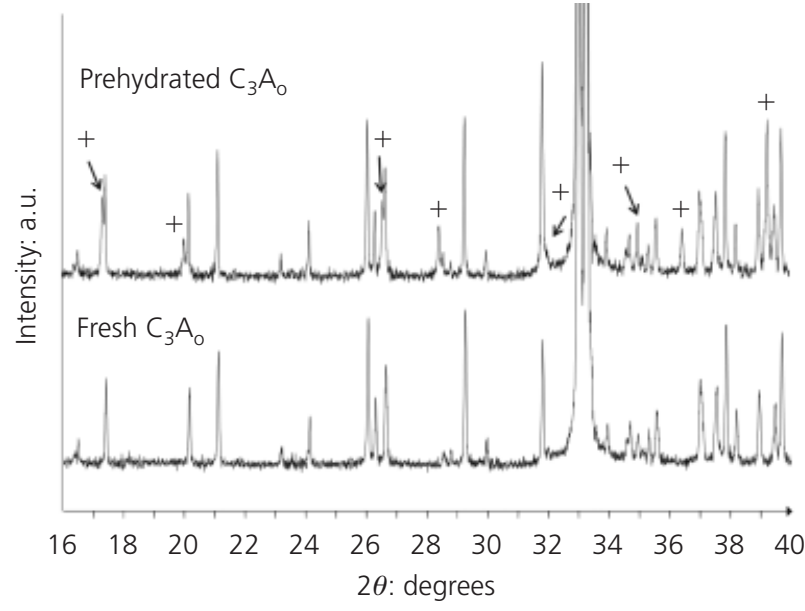

Figure 7. X-ray diffraction patterns recorded before and after exposure of orthorhombic $\mathrm{C}_{3} \mathrm{~A}$ to $\mathrm{RH}$ over a period of $55 \mathrm{~h}$ using the ramp regime: + - katoite (JCPDS no. 24-0217), unlabelled reflections belong to orthorhombic $\mathrm{C}_{3} \mathrm{~A}$

behaviour, orthorhombic $\mathrm{C}_{3} \mathrm{~A}$ with an initial average particle size ( $d_{50}$ value) of $10 \mu \mathrm{m}$ was ground to $5 \mu \mathrm{m}$ and $2 \mu \mathrm{m}$ respectively. Figure 8 shows the isotherms obtained for the three samples over $55 \mathrm{~h}$ of exposure. As expected, smaller samples, which possess higher specific surface areas, sorbed greater amounts of water. For example, the $\mathrm{C}_{3} \mathrm{~A}$ powder ground to $2 \mu \mathrm{m}$ sorbed $\sim 57 \%$ of its own mass, against $30 \%$ for the $10 \mu \mathrm{m}$ sample. To determine the impact of surface area, the values of sorbed mass of water per unit mass of phase were converted into values per unit of surface area, and the results shown in Figure 9. The amount of water sorbed per unit surface is independent of particle size and lies at $\sim 0.05 \mathrm{mg} / \mathrm{cm}^{2}$. Similarly, the onset of water uptake was independent of particle size. It started when RH reached $50 \%$, in good agreement with the results presented earlier (see Figure 3).

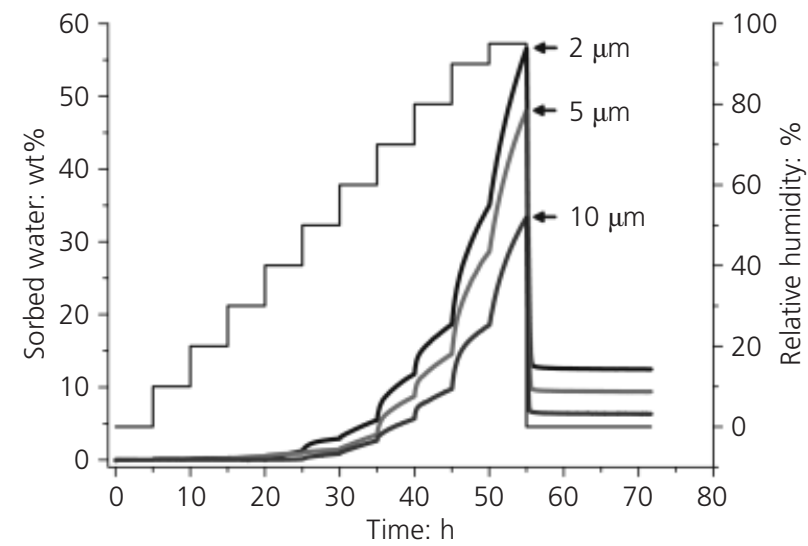

Figure 8. Water vapour sorption isotherms for orthorhombic $C_{3} A$ ground to average particle sizes of $10 \mu \mathrm{m}, 5 \mu \mathrm{m}$ and $2 \mu \mathrm{m}$ respectively, determined on a sorption balance at $20^{\circ} \mathrm{C}$ over a period of $55 \mathrm{~h}$ using step mode

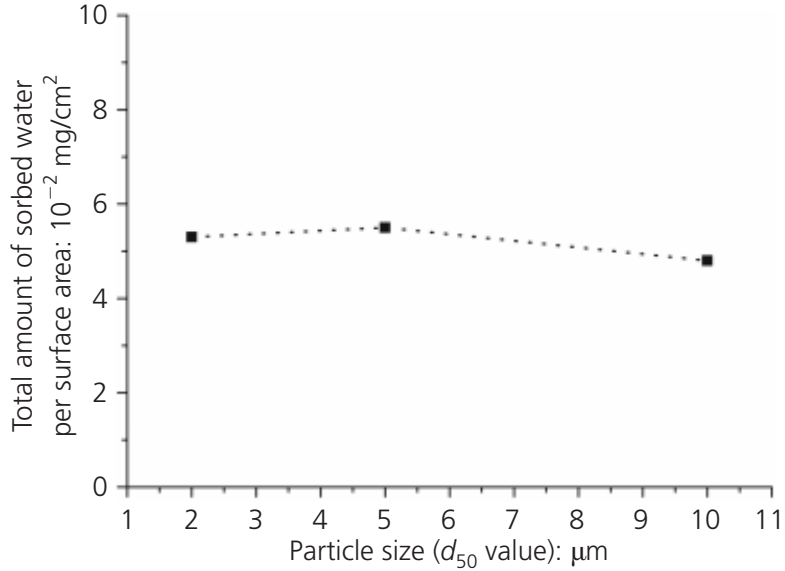

Figure 9. Plot of total amount of sorbed water per surface area (after exposure of sample to $\mathrm{RH}$ at $20^{\circ} \mathrm{C}$ for $55 \mathrm{~h}$ using the step mode) as a function of particle size ( $d_{50}$ value) of $C_{3} A_{\circ}$

\section{Binary mixtures}

\section{Dynamic water vapour sorption}

To study the behaviour of water sorption in the presence of sulfates, the cubic and orthorhombic $\mathrm{C}_{3} \mathrm{~A}$ polymorphs were exposed to a ramped $\mathrm{RH}$ regime in the presence of hemihydrate.

Figure 10 shows the cumulative amount of water sorbed by the binary mixtures. Below $64 \% \mathrm{RH}$, the sorption profiles of both $\mathrm{C}_{3} \mathrm{~A}$ polymorphs exhibit almost identical characteristics. Furthermore, both modifications show step-like mass increase over the range $34-60 \% \mathrm{RH}$, which can be attributed to the hemihydrate. This step also occurred in the mass profile of pure hemihydrate exposed to humidity (Dubina et al., 2011), where pure hemihydrate showed two onset points, one at $\sim 34 \% \mathrm{RH}$ and one at $\sim 78 \% \mathrm{RH}$, with an inflection point at $\sim 44 \% \mathrm{RH}$.

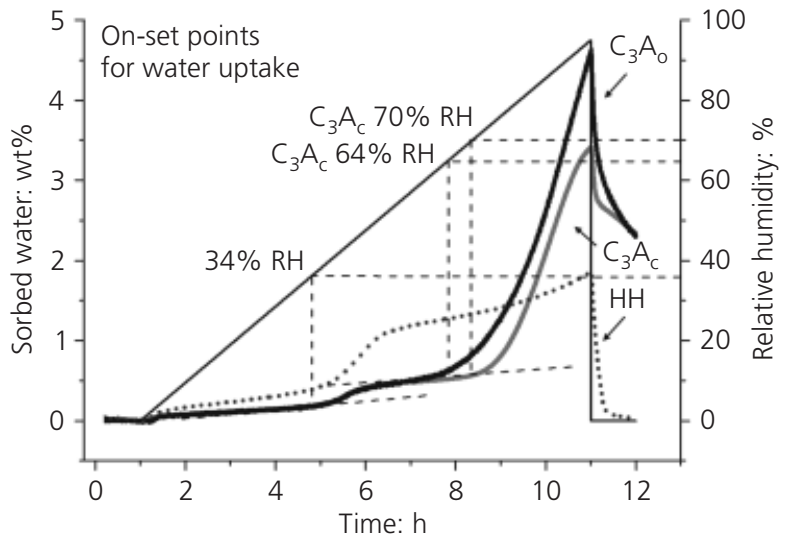

Figure 10. Water vapour sorption isotherms for pure $\mathrm{CaSO}_{4} \cdot 0 \cdot 5 \mathrm{H}_{2} \mathrm{O}$ and for cubic and orthorhombic $\mathrm{C}_{3} \mathrm{~A}$ dry-blended with hemihydrate, determined on a sorption balance at $20^{\circ} \mathrm{C}$ over a period of $11 \mathrm{~h}$ using the ramp regime 
The shapes of the water sorption profiles of the binary mixtures imply that at lower RHs, no chemical reaction occurs between $\mathrm{C}_{3} \mathrm{~A}$ and hemihydrate during pre-hydration; the mixtures sorb minimal amounts of moisture on their surfaces, possibly by hydrogen bonding. Additionally, for the binary mixture containing orthorhombic $\mathrm{C}_{3} \mathrm{~A}$, the onset point occurred at a slightly lower $\mathrm{RH}(64 \%)$ than for the binary mixture containing cubic $\mathrm{C}_{3} \mathrm{~A}$ $(70 \% \mathrm{RH})$. This suggests that the sodium ions present in orthorhombic $\mathrm{C}_{3} \mathrm{~A}$ lower the onset point.

Table 3 gives a comparison of the total amounts of water sorbed by cubic and orthorhombic $\mathrm{C}_{3} \mathrm{~A}$ at $20^{\circ} \mathrm{C}$ in the absence and presence of hemihydrate using the ramp regime. The table presents the amount of water sorbed by mass percentage and per unit of surface area $(\mathrm{BET})$ of $\mathrm{C}_{3} \mathrm{~A}$. The values show that when hemihydrate was present, both $\mathrm{C}_{3} \mathrm{~A}$ polymorphs sorbed higher amounts of water than in the absence of sulfate, with the effect on cubic $\mathrm{C}_{3} \mathrm{~A}$ being much more pronounced than for $\mathrm{C}_{3} \mathrm{~A}_{0}$. XRD analysis performed for the binary mixtures after exposure to moisture showed formation of ettringite for both modifications, confirming that $\mathrm{C}_{3} \mathrm{~A}$ reacts chemically with hemihydrate (Figure 11).

\section{$\mathrm{C}_{3} \mathrm{~A}$ polymorph Mass change after exposure to humidity}

\begin{tabular}{lccccc}
\cline { 5 - 6 } & \multicolumn{2}{c}{ Hemihydrate absent } & & \multicolumn{2}{c}{ Hemihydrate present } \\
\cline { 2 - 3 } \cline { 5 - 6 } & wt\% & $10^{-7} \mathrm{~g} / \mathrm{cm}^{2}$ & & wt $\%$ & $10^{-7} \mathrm{~g} / \mathrm{cm}^{2}$ \\
\hline Cubic & 0.92 & 11.8 & & 3.42 & 38.9 \\
Orthorhombic & 3.60 & 51.4 & & 4.60 & 54.8
\end{tabular}

Table 3. Comparison of the total amounts of water sorbed by cubic and orthorhombic $\mathrm{C}_{3} \mathrm{~A}$ at $20^{\circ} \mathrm{C}$ in the absence and presence of hemihydrate over $11 \mathrm{~h}$ using the ramp programme

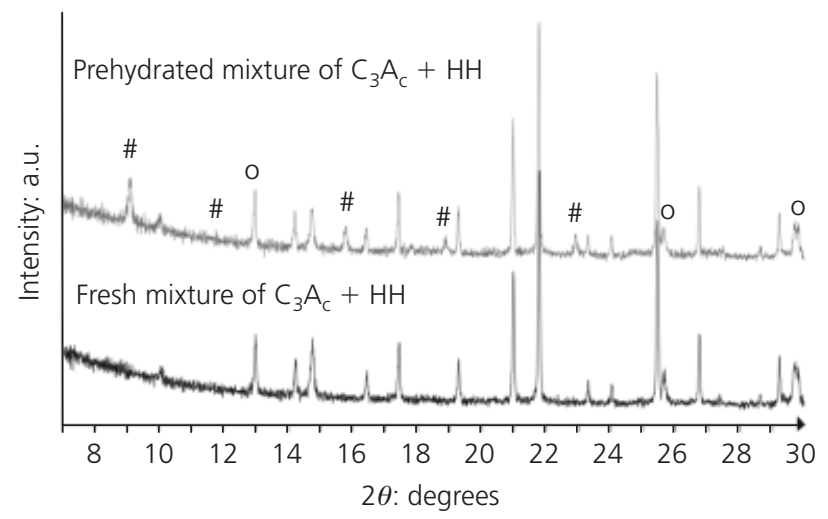

Figure 11. X-ray diffraction patterns of a binary mixture of cubic $\mathrm{C}_{3} \mathrm{~A}$ with hemihydrate recorded before and after exposure to $\mathrm{RH}$ over a period of $11 \mathrm{~h}$ using a ramp regime: \# - ettringite (JCPDS no. 42-1451), o - hemihydrate (JCPDS no. 41-0224), unlabelled reflections belong to cubic $C_{3} A$
In order to determine whether the pre-hydration reaction observed between $\mathrm{C}_{3} \mathrm{~A}$ and hemihydrate occurs with water vapour (gas molecules) or by way of condensation of water vapour followed by liquid-phase reactions, in situ ESEM monitoring of the prehydration of $\mathrm{C}_{3} \mathrm{~A}$ with hemihydrate was performed. For this purpose, the binary mixtures were exposed to $85 \% \mathrm{RH}$ at $4 \cdot 5^{\circ} \mathrm{C}$ for $1.5 \mathrm{~h}$ in the chamber of an ESEM instrument. Figure 12(a) clearly shows evidence of a liquid water film immediately at the beginning of the imaging. Later on, formation of nano-sized ettringite needles on the surface of $\mathrm{C}_{3} \mathrm{~A}$ (here: orthorhombic polymorph) was evidenced, as shown in Figure 12(b). This result is most interesting because ettringite formation is possible only if ions are dissolved from both $\mathrm{C}_{3} \mathrm{~A}$ and hemihydrate and then react in the liquid phase into ettringite. Thus, this experiment shows

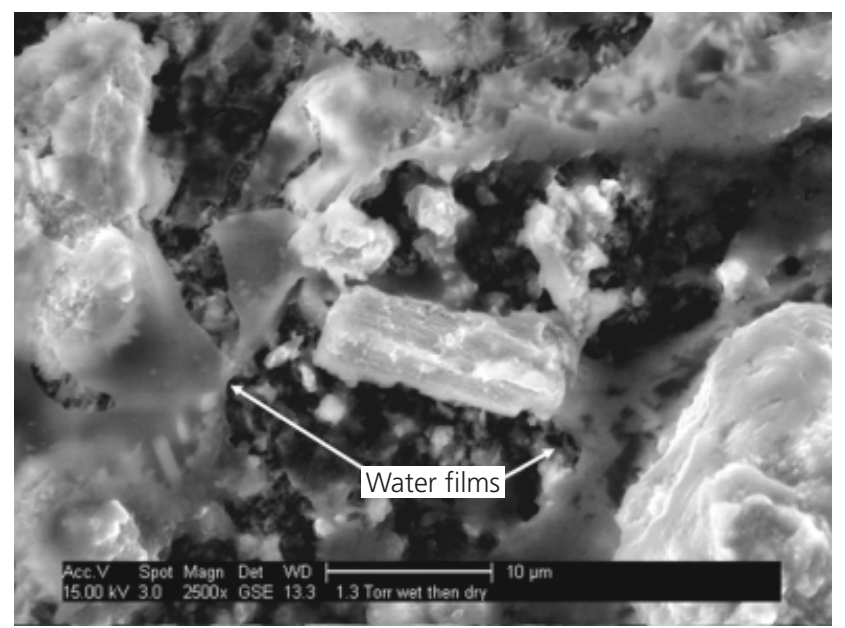

(a)

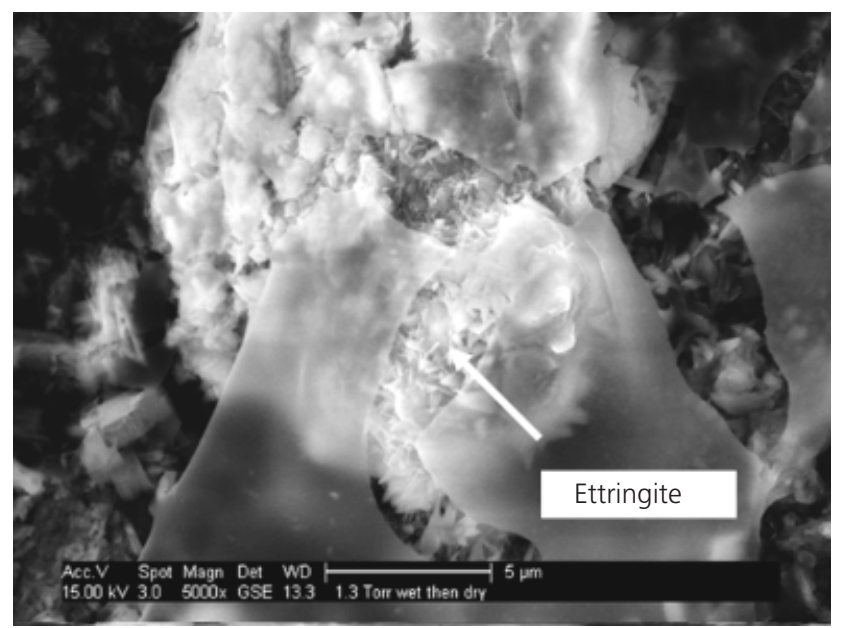

(b)

Figure 12. In situ ESEM monitoring of the pre-hydration of cubic $\mathrm{C}_{3} \mathrm{~A}$ with hemihydrate at $85 \% \mathrm{RH}$ : (a) formation of a liquid water film within minutes after moisture exposure; (b) ettringite needles

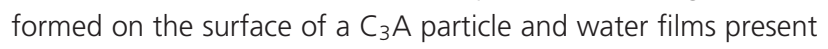
after $1.5 \mathrm{~h}$ of moisture exposure 
that pre-hydration mainly occurs by way of a liquid condensed water film and less from interaction with gaseous water molecules. It also confirms the observations made before for the individual clinker phases (see Figure 5).

At lower RHs $(<60 \%)$, the liquid water films were found to be thinner compared to higher RH values. Thicker water layers enable greater ion transport, thus accelerating the chemical reactions occurring between $\mathrm{C}_{3} \mathrm{~A}$ and hemihydrate and producing more early hydration products.

The same results were obtained for the binary mixture containing cubic $\mathrm{C}_{3} \mathrm{~A}$ (images not shown here). Again, liquid water films were found in-between the particles and on the surfaces, and nano-sized ettringite crystals were identified as pre-hydration products, thus confirming a reaction between dissolved ion species.

These findings suggest that during improper storage of actual cements, capillary condensation may occur between the cement particles, initiating partial surface hydration and resulting in products identical to those formed under normal hydration conditions. Also, this process will be accelerated for cements possessing particularly small particle sizes (e.g. CEM I 52.5 type). Such cement will require more careful storage than coarser cements.

\section{Static water vapour sorption}

Complementary to the dynamic water vapour sorption, a static method was employed to examine the behaviour of the binary mixtures over longer time periods $(21 \mathrm{~d})$ of exposure. Figure 13 shows the sorption isotherms obtained for both mixtures over the range $23-95 \% \mathrm{RH}$.

The results for both static and dynamic methods were found to be in good agreement. The onset points obtained by way of the dynamic method were comparable with those from static measurements. At relative humidities below the onset points, only minor amounts of water were sorbed (less than $2 \mathrm{wt} \%$ ). The binary mixture containing orthorhombic $\mathrm{C}_{3} \mathrm{~A}$ sorbed almost twice the amount of water compared to that containing cubic $\mathrm{C}_{3} \mathrm{~A}$. Ettringite was found in all samples pre-hydrated above the onset point, while below those $\mathrm{RH}$ values no ettringite was detected. The presence of sodium ions in orthorhombic $\mathrm{C}_{3} \mathrm{~A}$ leads to a more rapid water uptake by the mixture within the first $3 \mathrm{~d}$. This result implies that also in the presence of sulfate, sodium ions enhance the water uptake significantly, as was found before for the individual phases (see Figure 6).

In the SEM images of samples pre-hydrated for $21 \mathrm{~d}$, again, no ettringite was observed for the samples pre-hydrated below the onset point (Figure 14). Above the threshold, however, needle-like ettringite crystals were observed. It was noticed that the shape of the ettringite crystals can vary from very thin needles produced at lower RH (75\%) to long and thick crystals at 95\% RH.

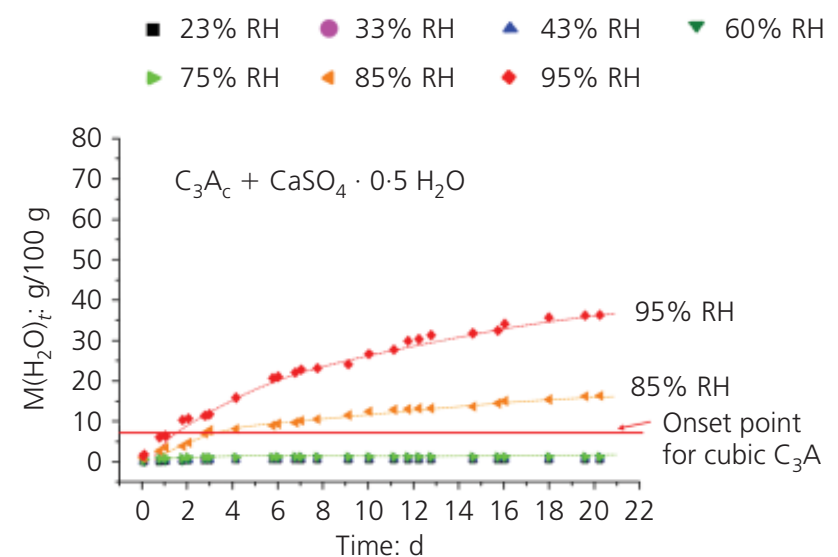

(a)

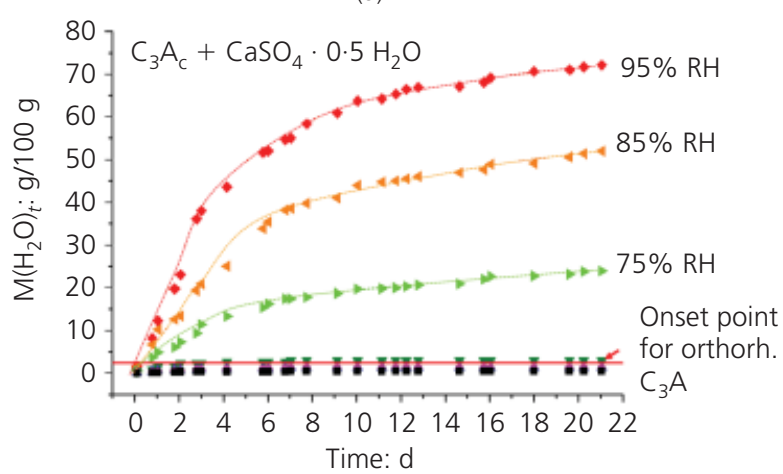

(b)

Figure 13. Water sorption isotherms for binary mixtures at $20^{\circ} \mathrm{C}$ and $23-95 \% \mathrm{RH}$ as a function of time: (a) cubic $\mathrm{C}_{3} \mathrm{~A}+$ hemihydrate; (b) orthorhombic $\mathrm{C}_{3} \mathrm{~A}+$ hemihydrate

\section{Conclusions}

Dynamic and static methods of water vapour sorption were used to follow the interactions of cubic and orthorhombic $\mathrm{C}_{3} \mathrm{~A}$ polymorphs with gaseous water in the absence and in the presence of calcium sulfate hemihydrate.

It was found that both polymorphs behave differently in the presence of water vapour. The sodium ions present in orthorhombic $\mathrm{C}_{3} \mathrm{~A}$ lower the onset point to $55 \% \mathrm{RH}$, compared to $80 \%$ for undoped cubic $\mathrm{C}_{3} \mathrm{~A}$. Additionally, $\mathrm{C}_{3} \mathrm{~A}_{\mathrm{o}}$ sorbs a higher amount of water, which is mainly bound physically, whereas $\mathrm{C}_{3} \mathrm{~A}_{\mathrm{c}}$ predominantly interacts with water chemically.

A linear relationship exists between the average particle size $\left(d_{50}\right.$ value) of a $\mathrm{C}_{3} \mathrm{~A}$ sample and the total amount of water sorbed. Smaller particles which possess higher surface areas take up more water. However, the amount of water sorbed per unit of surface area remained constant.

In the absence of sulfate, katoite was confirmed as pre-hydration product of $\mathrm{C}_{3} \mathrm{~A}$ by XRD. In the presence of calcium sulfate 
Impact of environmental moisture on $\mathrm{C}_{3} \mathrm{~A}$ polymorphs in the absence and presence

of $\mathrm{CaSO}_{4} \cdot 0.5 \mathrm{H}_{2} \mathrm{O}$

Dubina, Plank, Black and Wadsö

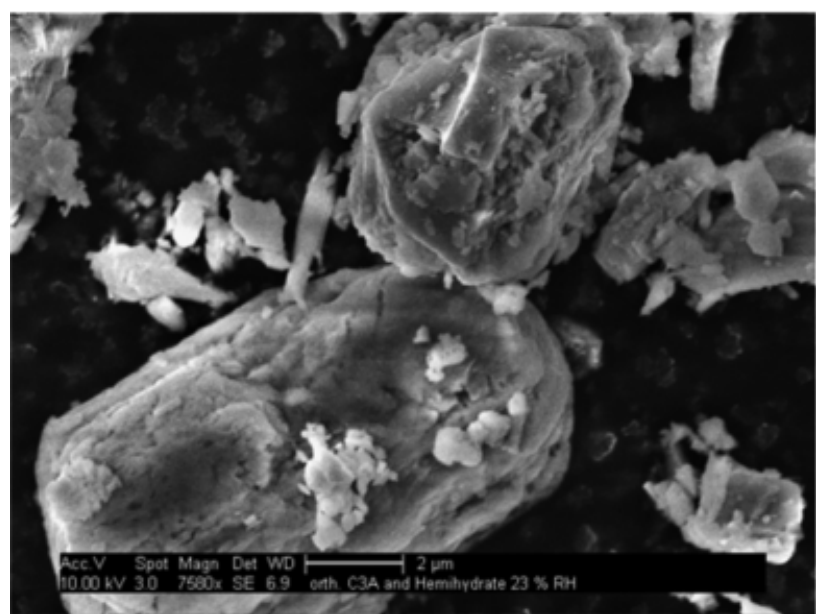

(a)

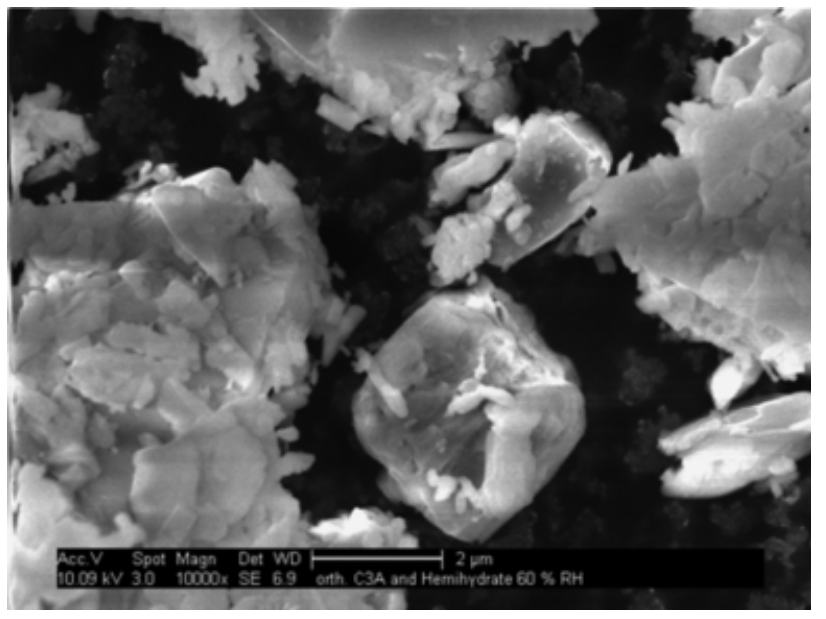

(c)

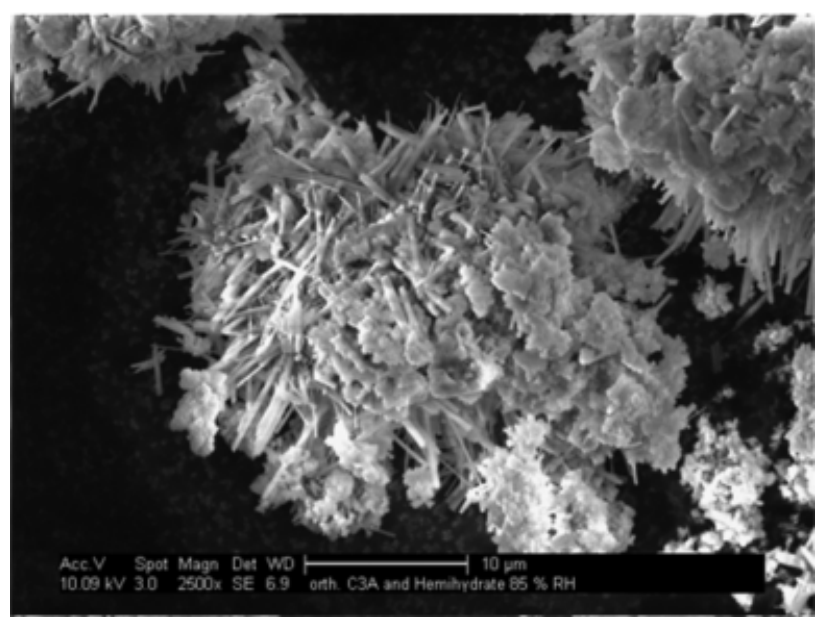

(e)

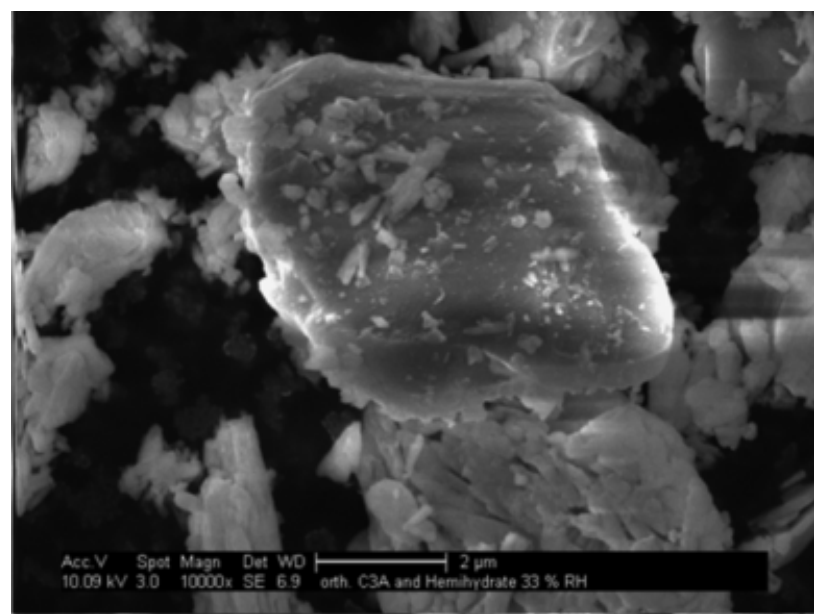

(b)

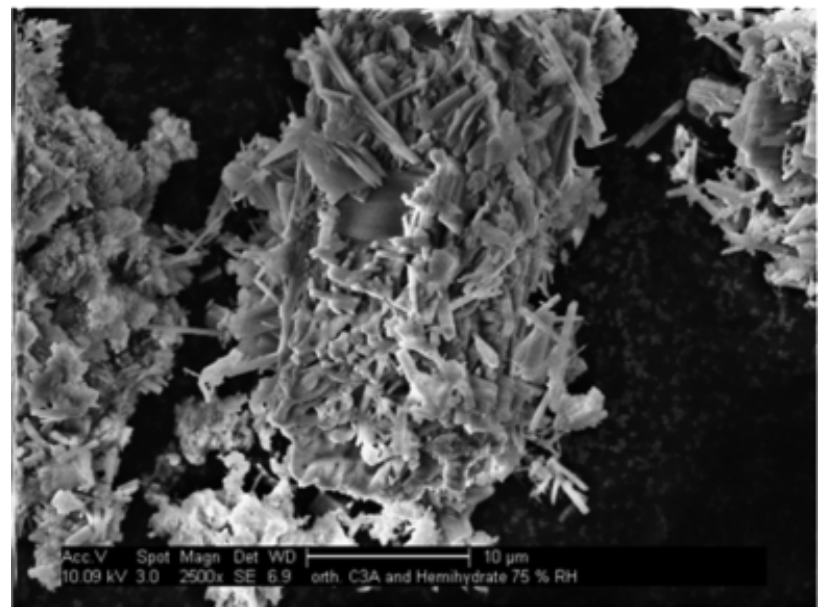

(d)

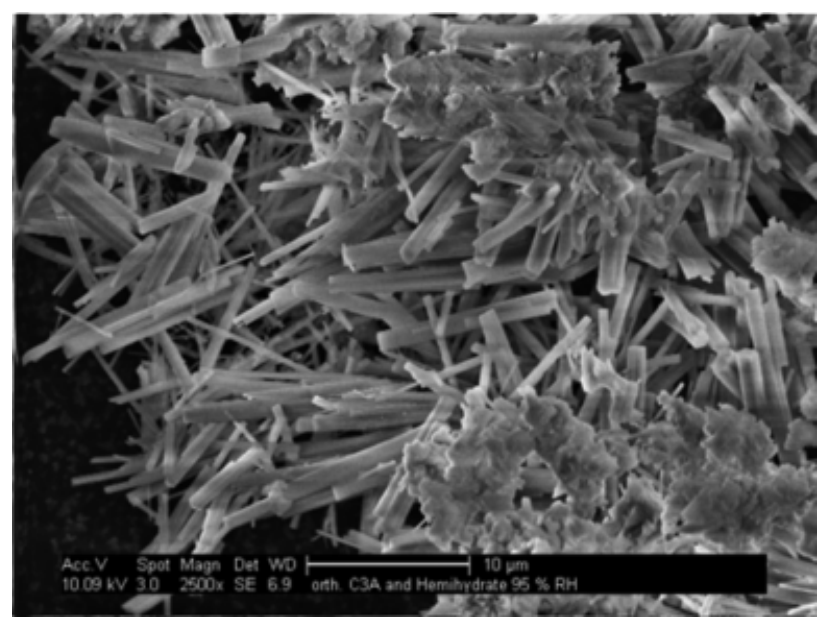

(f)

Figure 14. SEM images of orthorhombic $\mathrm{C}_{3} \mathrm{~A}$ pre-hydrated in presence of hemihydrate for $21 \mathrm{~d}$ at $20^{\circ} \mathrm{C}$ and at different

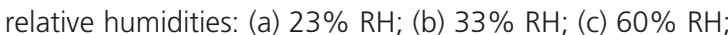
(d) $75 \% \mathrm{RH}$; (e) $85 \% \mathrm{RH}$; (f) $95 \% \mathrm{RH}$ 
hemihydrate, ettringite was found as the main pre-hydration product. ESEM imaging revealed that ettringite formation occurred by way of a condensed liquid water film. Obviously, pre-hydration not only involves surface interaction with gaseous water molecules; but also capillary condensation between $\mathrm{C}_{3} \mathrm{~A}$ particles occurs, allowing $\mathrm{C}_{3} \mathrm{~A}$ and sulfate to react according to the well-known clinker dissolution/oversaturation/precipitation scheme observed for conventional cement hydration. This finding is of fundamental importance because it signifies that during prehydration, similar hydrates are formed as during normal cement hydration when cement is mixed with water, although morphology might be dependent on the conditions. Ettringite crystals were shorter when $\mathrm{RH}$ was lower, and longer and thicker when $\mathrm{RH}$ increased. Below 70\% $\mathrm{RH}$, cubic $\mathrm{C}_{3} \mathrm{~A}$ did not react with calcium sulfate hemihydrate, while orthorhombic $\mathrm{C}_{3} \mathrm{~A}$ formed ettringite crystals already from $64 \% \mathrm{RH}$.

Thus, the experiments from this study suggest that when high amounts of Na-doped orthorhombic $\mathrm{C}_{3} \mathrm{~A}$ are present in a cement sample, it may undergo more pronounced pre-hydration during storage than a cement containing the same amount of cubic $\mathrm{C}_{3} \mathrm{~A}$.

Pre-hydration occurs when the ambient RH exceeds the threshold value at which moisture uptake begins (onset point). This implies that storing cements below this critical $\mathrm{RH}$ value would prevent pre-hydration. Therefore, throughout the production and storage period of a cement, ideally the ambient RH should be below the onset point of the most active clinker phases. However, under actual conditions in which cement is produced, stored, distributed and used, the control of RH to the required levels practically is impossible. Careful packaging and storage are the only measures which can help to minimise the effects from pre-hydration and to extend the shelf-life stability of cement.

\section{Acknowledgements}

E. Dubina is grateful to Nanocem (core project 7) for financial support of this work. Additionally, the authors would like to thank Holger König and Maciej Zajac, HeidelbergCement, Leimen, Germany as well as Ellis Gartner, Lafarge, France for their guidance and input in many discussions.

\section{REFERENCES}

Baquerizo L, Matschei T and Scrivener K (2012) Impact of water activity on the water content of cement hydrates. Proceedings of the Ibausil Conference, Bauhaus-Universität, Weimar, paper number 118

Black L, Breen C, Yarwood J et al. (2006) Hydration of tricalcium aluminate $(\mathrm{C} 3 \mathrm{~A})$ in the presence and absence of gypsum studied by Raman spectroscopy and X-ray diffraction. Journal of Materials Chemistry 16(13): 1263-1272.

Breval E (1977) Gas-phase and liquid-phase hydration of $C_{3} A$. Cement and Concrete Research 7(3): 297-304.

Breval E (1979) The effects of prehydration on the liquid hydration of $3 \mathrm{CaO} \cdot \mathrm{Al}_{2} \mathrm{O}_{3}$ with $\mathrm{CaSO}_{4} \cdot 2 \mathrm{H}_{2} \mathrm{O}$. Journal of the American Ceramic Society 62(7-8): 395-398.
Brown PW, Libermann LO and Frohnsdorff G (1984) Kinetics of the early hydration of tricalcium aluminate in solutions containing calcium sulfate. Journal of the American Ceramic Society 67(12): 793-795.

Deng C-S, Breen C, Yarwood J et al. (2002) Ageing of oilfield cement at high humidity: a combined FEG-ESEM and Raman microscopic investigation. Journal of Materials Chemistry 12(10): 3105-3112.

Dubina E, Black L, Sieber R and Plank J (2010) Interaction of water vapour with anhydrous cement minerals. Advances in Applied Ceramics 109(5): 260-268.

Dubina E, Wadsö L and Plank J (2011) A sorption balance study of water vapour sorption on anhydrous cement minerals and cement constituents. Cement and Concrete Research 41(11): 1196-1204.

Glasser FP and Marinho MB (1984) Early stages of the hydration of tricalcium aluminate and its sodium-containing solid solutions. Proceedings of the British Ceramic Society 35 : 221-235.

Greenspan L (1977) Humidity fixed points of binary saturated aqueous solutions. Journal of Research of the National Bureau of Standards - A, Physics and Chemistry 81A(1): 89-96.

Hansen FE and Clausen HJ (1974) Cement strength and cooling by water injection during grinding. Zement-Kalk-Gips 27(7): $333-336$.

JCPDS (2003) PDF-2 Release 2003, International Centre for Diffraction Data (ICDD), Newton Square, PA, USA.

Jensen OM (1995) Thermodynamic limitation of self-desiccation. Cement and Concrete Research 25(1): 157-164.

Jensen OM, Hansen P, Lachowski EE and Glasser FP (1999) Clinker mineral hydration at reduced relative humidities. Cement and Concrete Research 29(9): 1505-1512.

Kirchheim AP, Fernàndez-Altable V, Monteiro PJM, Dal Molin DCC and Casanova I (2009) Analysis of cubic and orthorhombic $\mathrm{C}_{3} \mathrm{~A}$ hydration in presence of gypsum and lime. Journal of Materials Science 44(8): 2038-2045.

Maltese C, Pistolesi C, Bravo A et al. (2007) Effect of moisture on the setting behavior of Portland cement reacting with an alkali-free accelerator. Cement and Concrete Research 37(6): 856-865.

Minard H, Garrault S, Regnaud L and Nonat A (2007) Mechanisms and parameters controlling the tricalcium aluminate reactivity in the presence of gypsum. Cement and Concrete Research 37(10): 1418-1426.

Pourchet S, Regnaud L, Perez JP and Nonat A (2009) Early $\mathrm{C}_{3} \mathrm{~A}$ hydration in the presence of different kinds of calcium sulphate. Cement and Concrete Research 39(11): 989-996.

Richartz W (1973) Effect of storage on the properties of cement. Zement-Kalk-Gips 26(2): 67-74.

Schmidt G, Bier TA, Wutz K and Maier M (2007) Characterization of the ageing behaviour of premixed dry mortars and its effect on their workability properties. Zement-Kalk-Gips International 60(6): 94-103. 
Sprung S (1978) Effect of storage conditions on the properties of cements. Zement-Kalk-Gips 30(6): 305-309.

Sylla HM (1975) Effect of clinker cooling on the setting and strength of cement. Zement-Kalk-Gips 28(9): 357-362.

Theisen K and Johansen V (1975) Prehydration and strength development of Portland cement. Journal of the American Ceramic Society 54(9): 787-791.
Whittaker M, Dubina E, Al-Mutawa F et al. (2013) The effect of prehydration on the engineering properties of CEM I Portland cement. Advances in Cement Research 25(1): 12-20, http://dx.doi.org/10.1680/adcr.12.00030.

Winnefeld F (2008) Influence of cement ageing and addition time on the performance of superplasticizer. Zement-Kalk-Gips International 61(11): 68-77.

\section{WHAT DO YOU THINK?}

To discuss this paper, please submit up to 500 words to the editor at www.editorialmanager.com/acr by 1 April 2014. Your contribution will be forwarded to the author(s) for a reply and, if considered appropriate by the editorial panel, will be published as a discussion in a future issue of the journal. 